\title{
Microstructure of ceramic foams
}

\author{
H.X. Peng ${ }^{\text {a }}$, Z. Fan ${ }^{\text {a }}$, J.R.G. Evans ${ }^{\text {b,* }}$, J.J.C. Busfield ${ }^{\text {b }}$ \\ ${ }^{a}$ Department of Materials Engineering, Brunel University, Uxbridge, Middlesex UB8 3PH, UK \\ ${ }^{\mathrm{b}}$ Department of Materials, Queen Mary and Westfield College, Mile End Road, London E1 4NS, UK
}

Received 13 May 1999; accepted 16 August 1999

\begin{abstract}
This paper describes the preparation of ceramic foams by expansion of a ceramic suspension based on a polyurethane system. The microstructure and degree of reticulation of the foamed ceramic were examined and analysed with the help of a simple geometrical model. Like the porous ceramics prepared by the replica processing method, these foamed ceramics possess open cells in a nearly equiaxed shape but the cell size is much finer. The ratio of the window size to the cell size is a useful parameter for characterising the geometry of the foam and is related to the qualitative concept of degree of reticulation. For a face centred cubic array of cells it is related geometrically to the volume fraction of porosity and this relationship is tested using microstructural measurements for a range of ceramic foams. (C) 2000 Elsevier Science Ltd. All rights reserved.
\end{abstract}

Keywords: Foams; Microstructure-final; $\mathrm{Al}_{2} \mathrm{O}_{3}$; Reticulation

\section{Introduction}

Reticulated ceramics are highly versatile porous materials which are used primarily in applications where fluid transport in the microstructure is required. These include molten metal filtration, hot gas filtration, catalyst supports, and such foams are now finding novel applications in the aerospace, electronics and pollution abatement fields among others. ${ }^{1}$

In order to meet the stringent requirements for some of these applications, there is a need to develop improved processing techniques. Several reviews of ceramic foams and their fabrication have recently appeared, including those by Saggio-Woyansky, Scott and Minnear ${ }^{2}$ Sepulveda ${ }^{3}$ and Rice. ${ }^{4,5}$

Among these, the polymer foam replication method patented by Schwartzwalder and Somers in $1963^{6}$ seems to be the most popular method employed to produce ceramic foam with open-cells. One possible drawback of this method is the tendency for it to leave either a hole or carbonaceous residue at the centre of each strut resulting from the pyrolysis of the polymer skeleton.

* Corresponding author. Tel.: +44-171-975-5501; fax: +44-181981-9804.

E-mail address: j.r.g.evans@qmw.ac.uk (J.R.G. Evans).
The nature of this characteristic defect is critical for the mechanical properties. ${ }^{7}$

A range of techniques for ceramic processing based mainly on aqueous media and known collectively as "gelcasting" "3,8,9 can also be applied to the preparation of ceramic foams. The increase in viscosity which allows shape to be retained in these processes is generally achieved by changes of $\mathrm{pH}$ or of temperature.

Aqueous polyurethane systems have been used to prepare ceramic foams by the incorporation of ceramic powder in slurry form before foaming. ${ }^{10,11}$ Conventional and commercially available polyurethane systems can also be used to produce fine $(<1 \mathrm{~mm}$ cell size $)$ ceramic foams. ${ }^{12}$ The present work extends this procedure and accounts for the microstructure of foams produced in this way.

\section{Experimental details}

\subsection{Materials}

A two-component, diphenylmethane di-isocyanatebased system designed to form a high voidage rigid polyurethane (PU) foam on curing was supplied by Baxenden Chemicals (Accrington, Lancs, UK). The grade was ISOFOAM RM6216W which is ideally suited 
for hand-mixing application. The resin component consisted of a pre-formulated mixture of polyols, catalysts, cell stabilisers, blowing agents and other additives which together with the isocyanate component determine the type of polyurethane foam produced. The isocyanate component was a grade of diphenyl methane di-isocyanate. The ceramic powder selected for this study was Alcan RA45E which is predominantly $\alpha$-alumina with $\mathrm{d}_{50}$ of $0.48 \mu \mathrm{m}$ donated by Alcan Chemicals, Gerrards Cross, UK. The commercially available ceramic foams used for comparison were grades PRO-AL10, 20, 25 and 30 supplied by Hi-Por Ceramics Ltd., Sheffield, UK. The densities of cylindrical samples deduced from geometry and mass were 10,17 , and $28 \%$ of theoretical respectively.

\subsection{Preparation of foams}

The sequence of operations for preparing sintered foams is depicted in Fig. 1. Based on previous work, ${ }^{12}$ the starting volume fraction of $20 \mathrm{vol} \%$ ceramic based on the polymer phase was selected. Above this level, void fraction of the foam falls steeply. ${ }^{12}$ In terms of uniformity of mixing, the ceramic powder was added to both the resin and the isocyanate component and stirred at $2400 \mathrm{rpm}$ for $300 \mathrm{~s}$. After dispersing the powder in the foam components, they were combined and stirred for $20 \mathrm{~s}$ at $2400 \mathrm{rpm}$. The mixture was poured into a wide shallow cardboard container allowing the foam to rise freely. After rising, the foam was left at room temperature for at least $24 \mathrm{~h}$ to ensure complete reaction.

\subsection{Pyrolysis and sintering}

Thermogravimetric analysis (TGA) was carried out on the foamed suspension in order to judge the pyrolysis and sintering schedules. A Perkin-Elmer Model TGS-2 analyser was used with a flow rate of air of $25 \mathrm{ml} / \mathrm{min}$

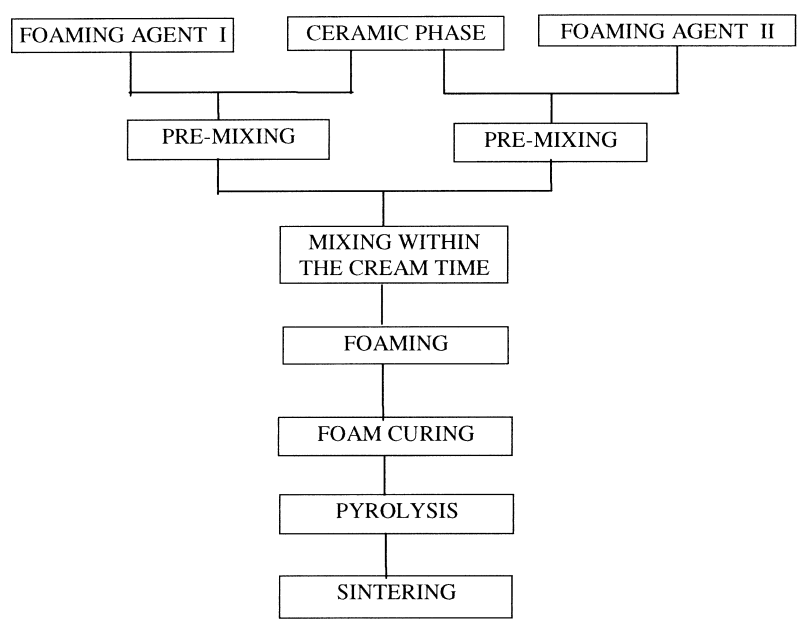

Fig. 1. Flow chart for the preparation of sintered ceramic foams. and a heating rate of $10^{\circ} \mathrm{C} / \mathrm{min}$. Pyrolysis of the foams was performed in a temperature programmable furnace with an air flow of about $4 \mathrm{l} / \mathrm{h}$ at a heating rate of $5^{\circ} \mathrm{C} / \mathrm{h}$ to $450^{\circ} \mathrm{C}$. Sintering was achieved by heating to $1650^{\circ} \mathrm{C}$ for $2 \mathrm{~h}$ with a ramp of $2^{\circ} \mathrm{C} / \mathrm{min}$. The shrinkage resulting from these processes was measured using a travelling microscope. A Jeol JX840 scanning electron microscope was used to examine fracture surfaces of both the PU-ceramic foam and the sintered ceramic foams. Cell diameters were measured on those cells which presented an equator in the fracture face. Where the image of windows was eliptical due to perspective, the largest diameter was recorded. This method allowed both widow and cell diameters to be measured concurrently. The software used to model the foam structure was Master Series (Ver. 6) produced by Structure Dynamics Research Group, SDRC, (Ohio, USA).

\section{Results and discussion}

The procedure used for mixing does not provide the high shear stress known to be needed to break up agglomerates in ceramic powders ${ }^{13}$ and, therefore, the microstructure can be expected to contain undispersed agglomerates. A further problem associated with mixing is that the time permitted for mixing of the two components is limited by the onset of reaction to about $60 \mathrm{~s}$. Nevertheless, the filled polyurethane rose sufficiently to produce foams of $125 \mathrm{~kg} \mathrm{~m}^{-3}$ corresponding to a void fraction of $93 \%$ based on the composite density of $1717 \mathrm{~kg} \mathrm{~m}^{-3}$.

A typical microstructure of a fracture surface of the unfilled polyurethane foam is shown in Fig. 2(a) and a corresponding micrograph of the filled foam is shown for comparison in Fig. 2(b). Generally, the ceramicpolymer foam has a similar structure to the unfilled foam. In neither case was there a perceptible anisotropy of cell shape associated with the rise direction. Most of the cells are closed with a thin membrane as the window. The several punctured windows seen in Fig. 2(a) are associated with the damage caused by specimen preparation during fracture near to the boiling point of liquid nitrogen. The main difference is the cell size which, for the unfilled foam is $590 \mu \mathrm{m}$ compared with $250 \mu \mathrm{m}$ for the filled foam. This can be attributed in part to the enhanced sites for heterogeneous nucleation offered by the powder and partly to the higher viscosity of the liquid which tends to resist expansion.

Fig. 3(a) shows the microstructure of the polymerceramic foam in more detail. It appears to show that the ceramic powder segregates to the struts as noted previously for $\mathrm{TiO}_{2}$ powder. ${ }^{12}$ This may be associated with the biaxial elongational flow of a thin film of liquid of similar thickness to the particle size $(\approx 1 \mu \mathrm{m})$. It has the advantage of producing an open cell structure because 


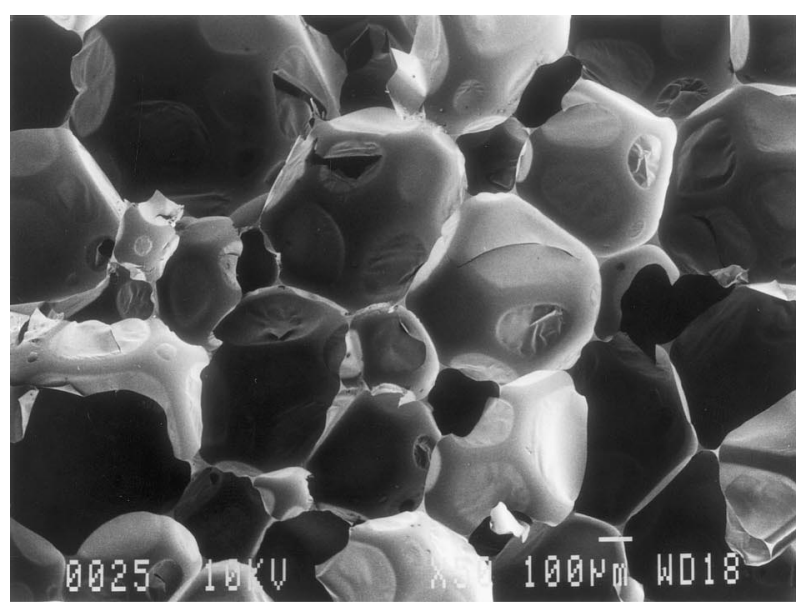

(a)

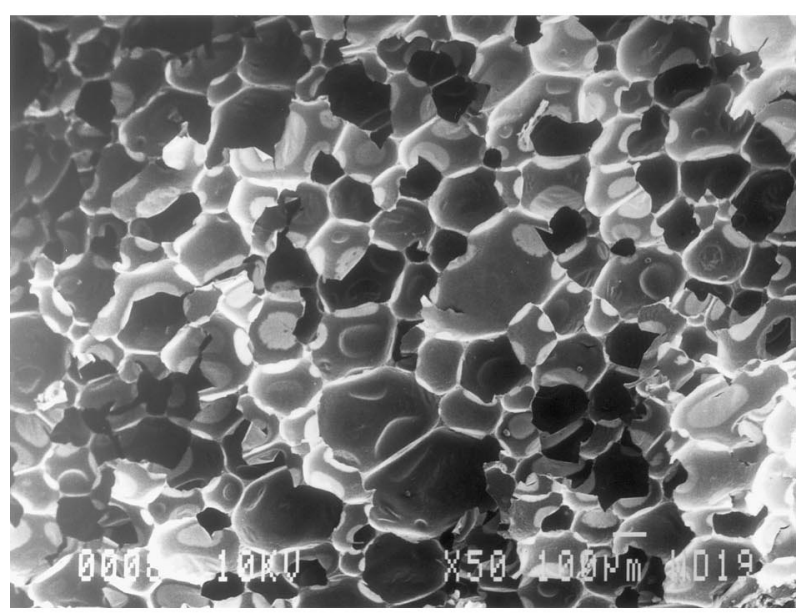

(b)

Fig. 2. Comparison of the structure of (a) the unfilled polyurethane foam and (b) the polyurethane-20 vol\% alumina foam.

the windows are lost upon pyrolysis. Thus, in a system such as this where segregation occurs, even if the polymer system is designed to give a closed cell structure, the ceramic foam produced therefrom is reticulated. This offers an additional mechanism for the development of reticulation to that proposed by Minnear ${ }^{11}$ which was that cell walls break at some characteristic thickness.

Fig. 3(b) shows (top centre) fracture sections through struts showing that they are free from the large internal skeletal relic of polymer as seen in ceramic foams made by slurry infiltration. The open window shown in this micrograph has perforated during the foaming process but the incidence of such windows throughout the unfired foam was less than $1 \%$. Fig. 3(c) shows, at a higher magnification, the powder depletion in the windows.

The thermogravimetric weight loss (Fig. 4) shows a three stage decomposition for the cured polyurethane system culminating in the loss of carbonaceous residue at $\sim 630^{\circ} \mathrm{C}$ in air. On this basis, the heating schedule described in Section 2 was devised for samples of $40 \mathrm{~mm}$

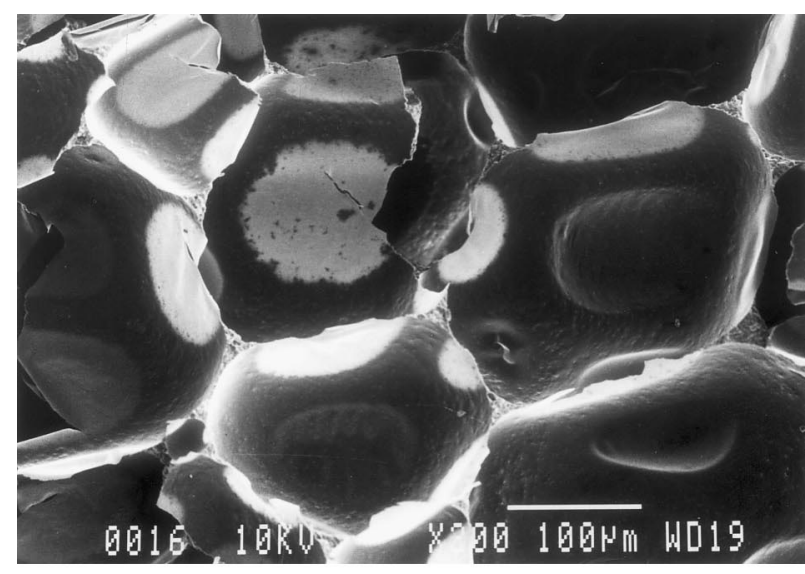

(a)

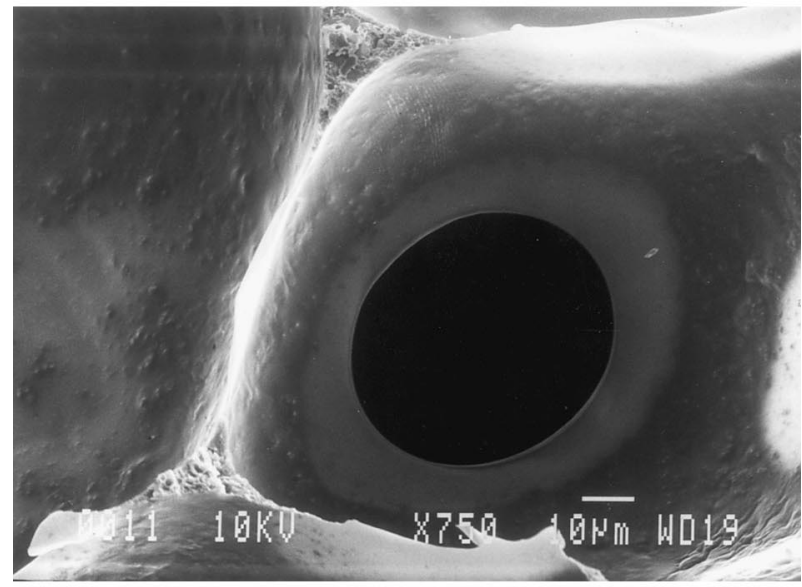

(b)

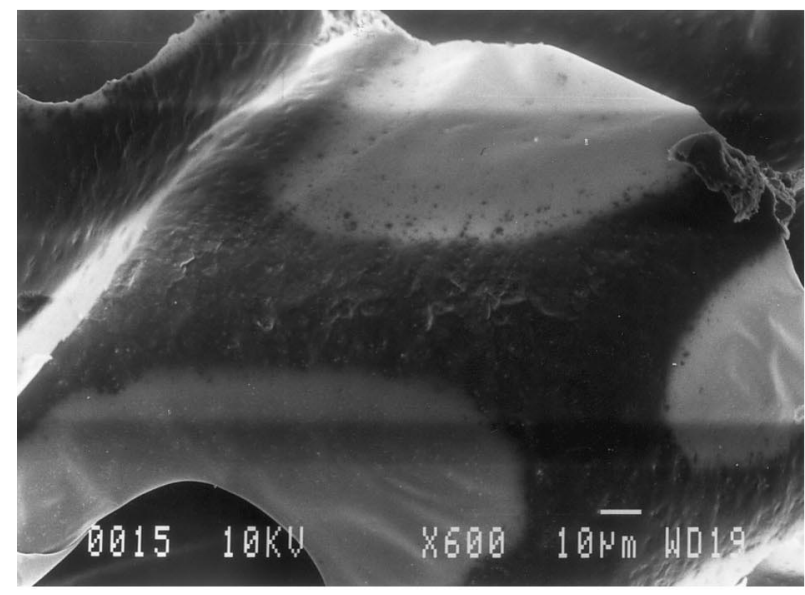

(c)

Fig. 3. Scanning electron micrographs of the polyurethane $20 \mathrm{vol} \%$ alumina foam showing (a) the uniformity of cell structure, (b) the presence of a small proportion of open windows at the foaming stage and (c) the apparent depletion of powder in the thinly drawn windows.

cube. Because of the low thermal conductivity, larger samples may need much lower heating rates.

The microstructure of the sintered ceramic foam is shown in Fig. 5. The fracture was created after sintering. 


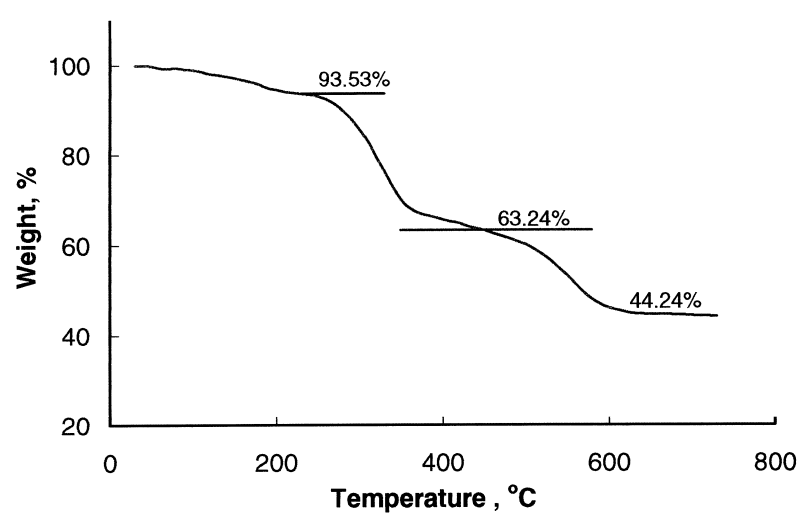

Fig. 4. Thermogravimetric curve for a $20 \mathrm{vol} \%$ alumina filled polyurethane foam heated in air at $10^{\circ} \mathrm{C} / \mathrm{min}$.

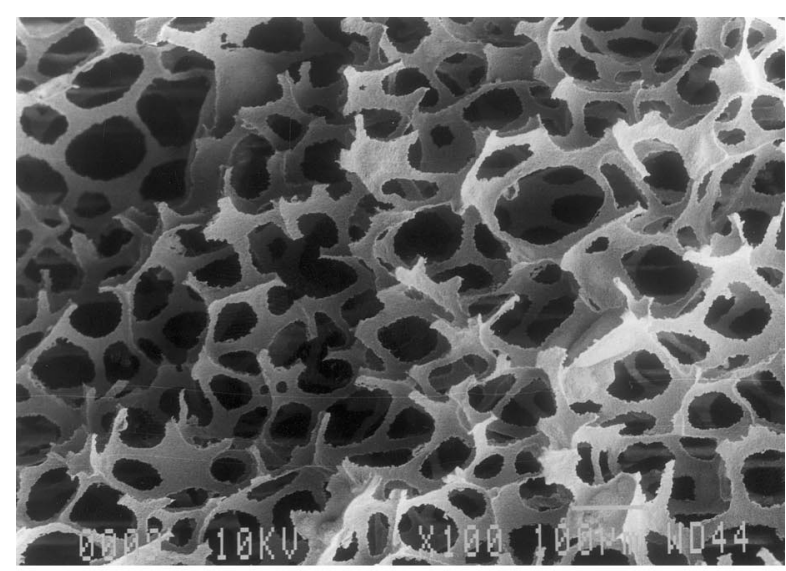

(a)

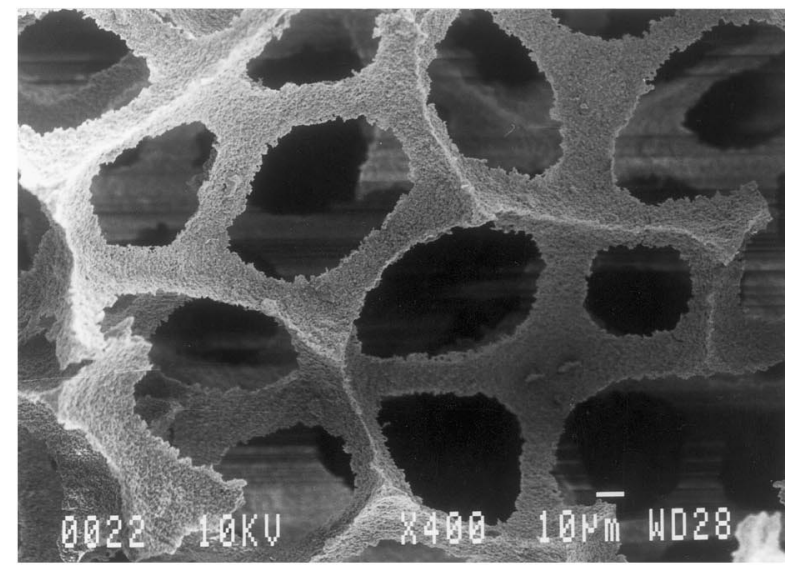

(b)

Fig. 5. Sintered ceramic foam at (a) low magnification showing an average cell size of $150 \mu \mathrm{m}$ and (b) high magnification.

The cell shape is polyhedral and the average cell diameter is $150 \mu \mathrm{m}$ with quite a narrow size distribution. This is due to the nature of the foaming process and will be discussed below. All the cells have open windows and the average diameter of the windows was $70 \mu \mathrm{m}$. A reticular structure was achieved after sintering and the degree of reticulation is high although this is a difficult microstructural feature to quantify.

Minnear characterised the reticulation using a slightly subjective scale of assessment which was related in a simple way to cell wall thickness and hence void fraction by considering a model of a stack of cubic cells with flat walls of uniform thickness. ${ }^{11}$ For a reticular foam produced by the foaming method used in the present work, the packing of near-spherical cells which have nearly the same size can be considered as a face centred array with co-ordination number 12. Many theoretical models for cellular materials assume that the cells or pores are packed in cubic array. ${ }^{5}$ There are many reports of models for cellular materials based on co-ordination numbers of 12 and 14 which are reviewed by Gibson and Ashby. ${ }^{14}$ In contrast Acosta et al., ${ }^{15}$ in studying the ratio of window diameter to cell diameter of ceramic foams made by the infiltration, pyrolysis and sintering of open cell polyurethane foams, adopted the body centred cubic packing structure with co-ordination number 8 . The cellular structures presented by the ceramic foams considered in the present work suggest that a co-ordination number of 12 is more appropriate. Supporting evidence for this kind of structure relating to a foamed ceramic can also be found in some commercial products. ${ }^{7}$ Typical microstructures of foamed 99.8\% alumina (ex Hi-Por Ceramics) with densities of 10 and $17 \%$ of theoretical are shown in Fig. 6 and they reveal an array of reasonably uniformly sized nearspherical cells.

The condition for an open window to form can be taken as the overlap of neighbouring cells, each considered spherical. A face centred cubic lattice is considered with lattice parameter, $a$, and with cells of diameter $D$, centred at lattice points. Considering the $<110>$ directions, the cells touch when

$D=a / \sqrt{2}$

which is the condition for an open cell structure. As $D$ increases, the circle formed by the intersection of nearest neighbour cells defines a window diameter $d$. Thus

$O \leqslant d / D<1 / \sqrt{2}$

The lower limit corresponds to the point contact of neighbouring cells at which the pore volume fraction $V_{p}=0.74$, while the upper limit corresponds to $D=a$ at which point the foam no longer contains a solid phase and the volume fraction of pores, $V_{p}=1$.

At intermediate cell intersections

$V_{p}=\frac{\frac{2}{3} \pi D^{3}-24 V_{I}}{a_{3}}$ 
where $V_{I}$ is the volume of one of the 24 full intersections between cells.

Since, from the geometry of a $\{100\}$ plane

$a=\sqrt{2}\left(D^{2}-d^{2}\right)^{1 / 2}$
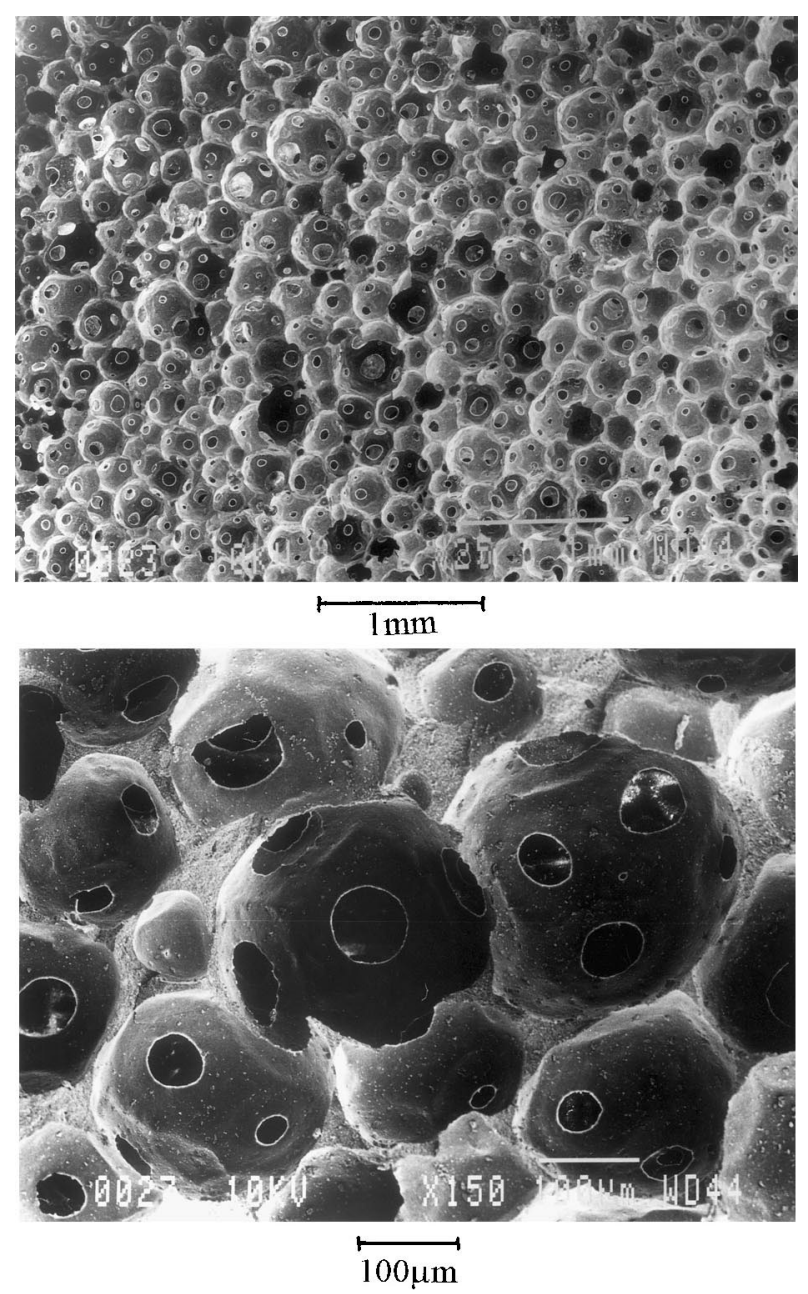

(a)

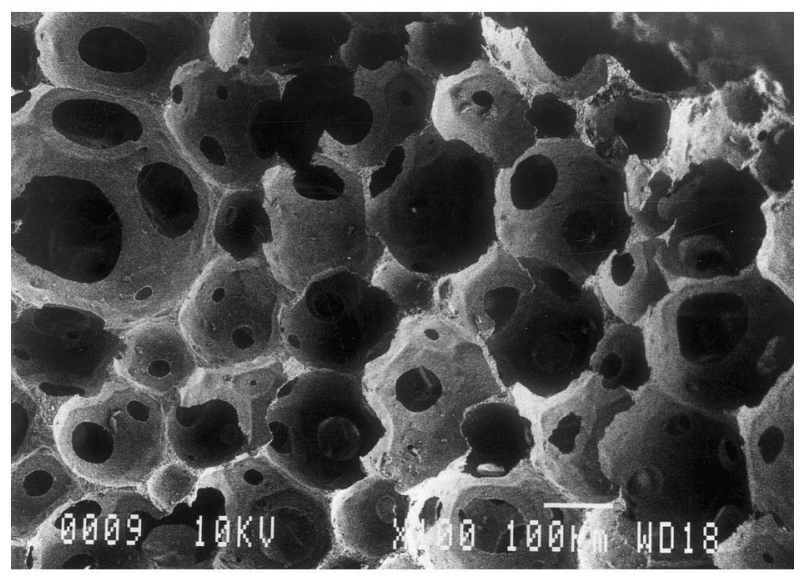

(b)

Fig. 6. A typical microstructure of commercially available high porosity alumina foam (Hi-Por Ceramics Ltd. Sheffield, UK) with a relative density of (a) $17 \%$ and (b) $10 \%$. and the volume of an intersection is given by

$$
\begin{aligned}
& V_{I}=\frac{\pi}{6}\left(D^{3}+\frac{a^{3}}{4 \sqrt{2}}-\frac{3 D^{2} a}{2 \sqrt{2}}\right) \\
& V_{p}=\frac{\pi}{\sqrt{2}}\left[\frac{3}{1-k^{2}}-\frac{5}{3}\left(\frac{1}{\sqrt{1-k^{2}}}\right)^{3}-1\right]
\end{aligned}
$$

where $k=d / D$.

Thus, the ratio of the window to cell diameters is directly related to the pore volume fraction and this allows a comparison with the microstructure. A plot of $V_{p}$ vs $d / D$ is shown in Fig. 7 for $0.74<V_{p}<1.0$. The data in this figure agree with mensuration deduced from the images generated on the SDRC design software. Using such software packages, the co-ordination number can be varied by exploring different packing arrangements and iteration can be applied to modify the structure according to a minimum solid area criterion. In this work such a criterion has not been applied and so the computer simulation shows that the structure breaks up at $d / D=0.5$ corresponding to $V_{p}=98 \%$. Eq. (6) also begins to fail at about $V_{p}=97.7 \%$ because it does not exclude secondary overlaps. The unit cell in the computer simulation is shown in Fig. 8 for a foam of porosity $88 \%$ and $d / D=0.37$ indicating the spherical overlapping cells and windows. The relative strut thickness deviates from that observed in the microstructure simply because the shape has not been constrained to minimise the solid surface area.

Fig. 7 shows the monotonic increase in window diameter as the void fraction increases and can be compared directly with microstructural measurements. For the foams described in Ref. 12, sample 54/PM gave $d / D=0.28$ and contained $80 \%$ voids; the model predicts $V_{p}=0.825$. Foam $46 / \mathrm{PM}$ gave $d / D=0.38$ and had $V_{p}=93 \%$; the model predicts $89 \%$. There is a substantial spread associated with these values of $d / D$ which is reflected in the $95 \%$ confidence limits in Fig. 7. Foam $60 / \mathrm{PM}$ with $68 \%$ voids showed an almost completely closed cell structure in the sintered state as predicted by this model. The data points corresponding to these values are superimposed on the model curve in Fig. 7.

The alumina foam shown in Fig. 5 of this paper has $d / D=0.45$ and the corresponding value of $V_{p}$ based on this model is $94 \%$ which corresponds to the measured porosity. For the foams shown in Fig. 6(a) and (b), the measured values of $d / D$ were 0.26 and 0.34 and the corresponding measured void fractions were 0.83 and 0.90 . The model gives values of $V_{p}$ of 0.82 and 0.86 respectively. A more dense ceramic foam from this family with measured porosity of 0.78 gave an average value of $d / D$ of 0.1 but was not plotted in Fig. 7 because the microstructure showed that the cell diameter was far from uniform and the geometry of the model did not therefore apply. 


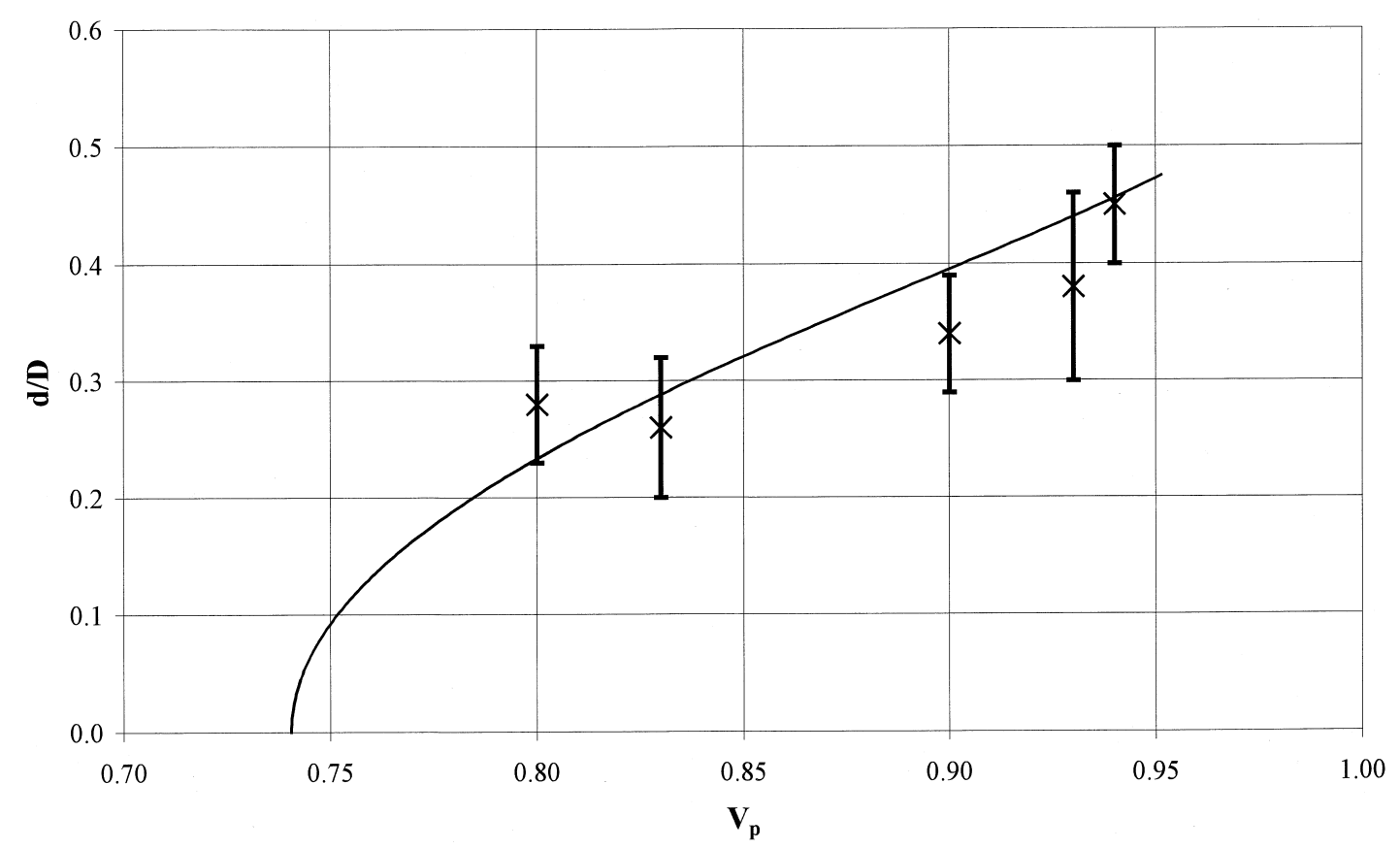

Fig. 7. Plot of window diameter/cell diameter ratio $(d / D)$ as a function of porosity $\left(V_{p}\right)$ for a face centred cubic array of cells [Eq. (6)]. The superimposed data points are for the sintered ceramic foam described in this work. The error bars represent $95 \%$ confidence limits.

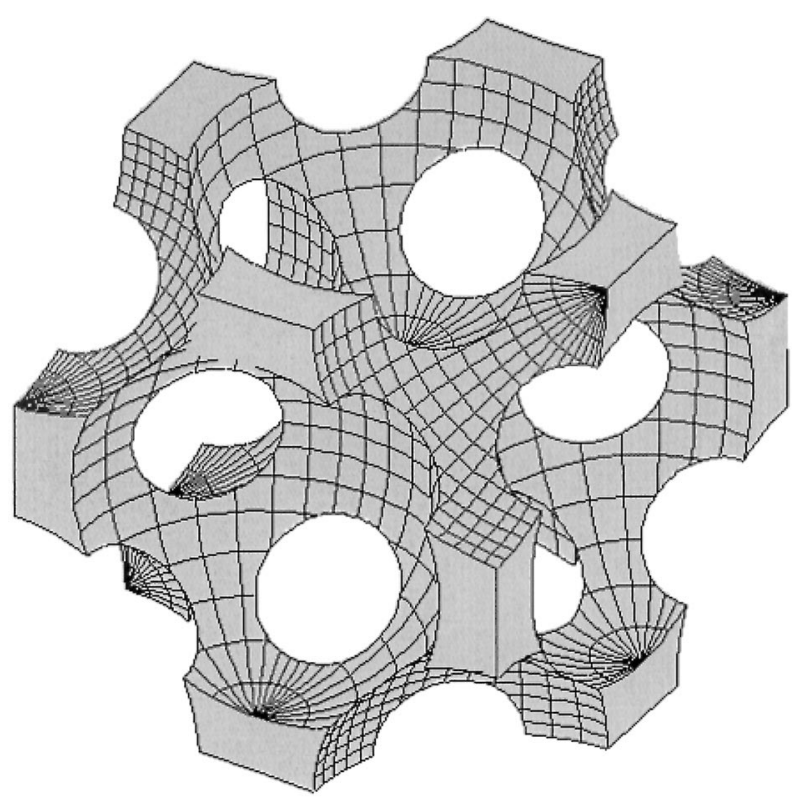

Fig. 8. The structure cell of the face centred cubic foam with $d / D=$ 0.37 and $V_{p}=0.88$ prepared by computer simulation.

The foaming mechanisms of polymeric systems are well understood as illustrated by Saunders. ${ }^{16}$ They include bubble formation, growth and stabilisation. When a bubble is first formed, it is a sphere surrounded by a liquid phase. As more gas is generated, new bubbles may form if gas concentration sufficiently exceeds the supersaturation at which the first bubbles were formed. Alternatively, it may diffuse from the liquid phase into existing bubbles, causing them to become larger. It may also diffuse to the external surface. All these processes are competitive and the result is that all bubbles in the foam are expected to be similar in size because they were initiated at practically the same time and competed with each other for dissolved gas. As shown in Figs. 5 and 6, the cell size distribution for the foamed ceramic is quite narrow.

During the foaming process, bubble walls in low viscosity systems may be thinned by drainage due to gravity and also by capillary action. Capillary pressure at the junction of two or more ribs in a cell is lower than in the membrane because of the greater curvature of the liquid-vapour interfaces. This is considered to promote flow from the membranes to the ribs, leading to thinning of cell walls and sometimes to rupture.

The viscosity of the liquid phase during the foaming process plays a key role in bubble growth and stabilisation. The introduction of ceramic powder results in an increase in viscosity which can be predicted by generalised contiguity models. ${ }^{17}$

At the low volume fractions of ceramic used in this work simple models based on an extension of Einstein's equation by the addition of terms of higher order of $\phi$ can be used to estimate the effect of introducing ceramic powder and these are reviewed by Barnes. ${ }^{18}$ One such expression proposed by Batchelor ${ }^{19}$ is:

$\eta_{s}=\eta_{0}\left(1+2.5 \phi+6.2 \phi^{2}\right)$

where $\eta_{s}$ is the viscosity of the suspension, $\eta_{0}$ is the viscosity of the suspending medium and $\phi$ is the volume fraction of particles. At $\phi=0.2$ the increase in viscosity 
is $75 \%$. There is some evidence that such models, deduced for shear flow regimes can also be applied to the biaxial elongational mode which is involved in foam production. $^{20}$ During the foaming process a higher viscosity does not permit the membrane to flow fast enough to expand in response to the pressure of blowing agent gas.

\section{Conclusions}

Open cell ceramic foams with fine $(150 \mu \mathrm{m})$ cell size, uniform cell size distribution and a high degree of reticulation have been prepared from a commercially available two-part polyurethane system. The foam does not suffer from an inherent internal defect in the struts which is found in foams prepared by slurry infiltration. A simple model based on the face centred cubic lattice adequately relates the window to cell diameter ratio with the void volume fraction and this correlates with microstructural measurements both on foams made by the technique described in this paper and on commercially available high porosity ceramic foams.

\section{Acknowledgements}

The authors are grateful to EPSRC for funding this work under Grant No. GR/L80553.

\section{References}

1. Strom, L. A., Sweeting, T. B., Norris, D. A. and Morris, J. R., Novel applications of fully sintered reticulated ceramics. Mat. Res. Soc. Symp. Proc., 1995, 371, 321-326.

2. Saggio-Woyansky, J., Scott, C. E. and Minnear, W. P., Processing of porous ceramics. Am. Ceram. Soc. Bull., 1992, 71(11), 1674-1682.

3. Sepulveda, P., Gelcasting foams for porous ceramics. Am. Ceram. Soc. Bull., 1997, 76(10), 61-65.
4. Rice, R. W., The porosity dependence of physical properties of materials: a summary review. Key Eng. Materials, 1996, 115, 119.

5. Rice, R. W., Porosity of Ceramics. Marcel Dekker, NY, 1998.

6. Schwartzwalder, K. and Somers, A. V., Method of making porous ceramic articles, U.S. Patent No. 3090094. May 21, 1963.

7. Lange, F. F. and Miller, K. T., Low density ceramics fabricated from reticulated polymer substrates. Adv. Ceram. Mater., 1987, 2, $827-831$.

8. Smith, R. T., Sambrook, R. M. and Binner, J. G. P., Novel processing of foam ceramics, Advances in Porous Ceramics, Mat. Res. Symp. Proc., Materials Research Society, 1995, 371, 279284.

9. Hirschfeld, D. A., Li, T. K. and Liu, D. M., Processing of porous oxide ceramics. Key Engineering Materials, 1996, 115, 65-80.

10. Wood, L. L., Messina, P. and Frisch, K. C., Method of preparing porous ceramic structures by firing a polyurethane foam that is impregnated with inorganic materials, U.S. Patent No. 3833386, 3 September, 1974.

11. Minnear, W. P., Processing of foamed ceramics. In Ceramic Transactions 26: Foaming Science and Technology for Ceramics, ed. M. J. Cima. Am. Ceram. Soc, Westerville, OH, 1992, pp. 149156.

12. Powell, S. J. and Evans, J. R. G., The structure of ceramic foams prepared from polyurethane-ceramic suspensions. Materials and Manufacturing Processes, 1995, 10, 757-771.

13. Song, J. H. and Evans, J. R. G., Assessment of dispersion of fine ceramic powders for injection moulding and related processes. $J$. Eur. Ceram. Soc., 1993, 12, 467-478.

14. Gibson, L. J. and Ashby, M. F., Cellular Solids, 2nd edn. CUP, Cambridge, 1997 (pp. 15-25).

15. Acosta, F. A., Castillejos, A. H., Almanza, J. M. and Flores, A., Analysis of liquid flow through ceramic porous media used for molten metal filtration. Met. Mater. Trans., 1995, 26B, 159 171.

16. Saunders, J. H. and Hansen, R. H., The mechanism of foam formation. In Plastic Foams, Part I, ed. K. C. Frisch and J. H. Saunders. Marcel Dekker, New York, 1972, pp. 23-108.

17. Fan, Z. and Boccaccini, A. R., A new approach to the effective viscosity of suspensions. J. Mat. Sci., 1996, 31, 2515-2521.

18. Rheology of suspensions. In An Introduction to Rheology, Rheology Series, 3, ed. H. A. Barnes, J. F. Hutton and K. Walters, Elsevier Science Publishers, Amsterdam, 1989; pp. 115-140.

19. Batchelor, G. K., The effect of Brownian motion on the bulk stress in a suspension of spherical particles. J. Fluid Mech., 1997, 83, 97-117.

20. Greener, J. and Evans, J. R. G., Uniaxial elongational flow of particle-filled polymer melts. J. Rheol., 1998, 42, 697-709. 